\title{
Biblioteca Escolar de Instituição Particular de Ensino: relato de experiência
}

\author{
The School Library of an Educational Private Institution: experience report
}

Andreia das Dores Silva Julio

Graduação pela Escola de Biblioteconomia da UNIFOR-MG, especialista em Organização da Informação em Contextos Digitais pela UFMG. Bibliotecária do Instituto Educacional Novos Tempos - Contagem/MG.

E-mail: andreiasjulio@hotmail.com

\section{Resumo}

Relata a experiência de organização de uma biblioteca escolar de uma instituição particular de ensino, descrevendo o processo de automatização e o desenvolvimento de projetos de incentivo a leitura, fazendo dela um recurso didático-pedagógico a ser utilizado para a integração e dinamização do processo ensinoaprendizagem. Para tanto, valeu-se de estratégias inovadoras e projetos de literatura infantil e juvenil. Dessa maneira, a biblioteca escolar assume seu papel educacional e cultural de acordo com os novos paradigmas da sociedade da informação.

Palavras chave: Biblioteca Escolar; Incentivo à leitura; Automatização

\begin{abstract}
Reports the experience of organizing a school library in a private school in Brazil, describing the process of automation and the development of projects to encourage reading, making the library a pedagogical-didactic resource to be used for the integration and promotion of the teaching-learning process. Therefore, innovative strategies were used and projects for promotion of reading were developed. Thus, the school library takes its educational and cultural role according to the new paradigms of the information society.
\end{abstract}

Keywords: School Library; Incentive reading; Automation

\section{Introdução}

O Instituto Educacional Novos Tempos, é uma instituição particular de ensino e atende alunos do Maternal ao Ensino Médio. Fundada a 15 anos, dispõe de ótima estrutura física, sendo considerada uma das melhores escolas de Contagem.

A Biblioteca foi fundada em janeiro de 2000, e inicialmente foi organizada por auxiliares de biblioteca, com formação técnica pelo CTE (Consultoria Técnica Educacional) em Belo Horizonte.

Adotava-se um sistema de classificação bibliográfica condensada fornecido pela CTE sugerida para utilização em pequenas bibliotecas públicas. Trata-se de uma tabela de 41 
páginas, divididas em dois anexos: o primeiro abrange todas as classes em três dígitos, e o segundo contempla o índice de Assuntos de Classificação organizados em ordem alfabética.

Para o controle de empréstimo, era confeccionada uma ficha para cada aluno, na qual se registrava os dados do livro emprestado, data de empréstimo e devolução.

O acervo era composto por aproximadamente 800 livros, compreendendo literatura infantil, juvenil, livros didáticos e gibis.

Após assumir a Biblioteca em 2003 e buscando modificar a realidade da biblioteca, elaborou-se um diagnóstico para estruturação e automatização da instituição afim de fornecer condições que pudessem representar uma contribuição aos usuários.

Para realizar este trabalho, procurou-se realizar um diagnóstico e aplicar ao projeto, um conjunto de conceitos e tecnologias que favorecessem a coleta e a organização das informações.

Um elemento importante que representa uma forte contribuição é o que se refere a coleta de informações pessoais e sociais da instituição. Normalmente utiliza-se de entrevistas para obter informações relacionadas a rotina da instituição. Porém, o que se observa é que quando alguém é entrevistado e deve responder inúmeras questões, as vezes em pouco tempo e, quando não o faz, em uma posição altamente tendenciosa, ocorre a perda da espontaneidade.

Como se trata de uma empresa familiar, várias decisões já haviam sido instituídas, cabendo na ocasião, acatar as decisões tomadas e adequá-las à realidade.

\section{Automatização da Biblioteca}

Em 2003, a escola mantinha contrato com a AIX Sistemas, uma empresa especializada no desenvolvimento de softwares para instituições de ensino. Foi solicitado a ela o desenvolvimento de um software para automatização da biblioteca. A instituição apresentou como solução o GIZ Biblioteca, módulo oferecido pela empresa AIX Sistemas a época.

Tratava-se de um software simples, que ainda estava em construção, e contava com a cooperação de vários usuários do sistema para a sua melhoria. Dentre os recursos oferecidos, suas principais funcionalidades eram: 
- Cadastro de acervos, autores, assuntos, idiomas, coleções, localização, editores;

- Cadastro de motivos de indisponibilidade do acervo;

- Consulta de empréstimos por usuário ou exemplar;

- Devolução por exemplar e por usuário;

- Emissão de carteiras de usuário, etiquetas de lombada e códigos de barras;

- Emissão de penalização por devoluções em atraso com multas ou com dias de impedimento de realização de empréstimo;

- Bloqueio de empréstimo para usuários com devoluções em atraso.

Infelizmente o sistema apresentou alguns erros, que não foram corrigidos conforme a necessidade da instituição, e após várias tentativas, foi decidido interromper o contrato com a Empresa em relação a este módulo.

Em 2007 foi apresentado o PHL, como uma das opções para substituição do sistema da AIX, considerando-se que a interface do sistema era amigável e sendo a base de dados em SQL, haveria compatibilidade na importação dos dados. A versão adotada pela escola, foi a monousuário. Esta versão é gratuita e bastante satisfatória, mas, em 2010 começou a apresentar falhas, devido ao tamanho do acervo a gerenciar, e o departamento de informática da instituição não conseguia suporte técnico.

A escola propôs então, a implantação de um sistema próprio de Biblioteca, em parceria com o DTI (Departamento de Tecnologia e Informática), que contemplaria todas as necessidades da biblioteca, incluindo o módulo WEB, indispensável para se consultar o acervo bibliográfico, pesquisar empréstimos, realizar reservas, consultar a posição na fila de espera, e efetivar renovações, disponível em WWW.ient.com.br/biblioteca.

A experiência de criação do sistema BIENT (Biblioteca Instituto Educacional Novos Tempos) foi muito positiva, pois a biblioteca contava com o suporte do DTI, diariamente e conseguiu-se importar com facilidade todo o acervo, que atualmente é composto por mais de 25.000 exemplares, compreendendo Literatura Infantil, Juvenil, Livros Didáticos, Paradidáticos, Enciclopédias, Dicionários, Gibis, Fantoches, Cds, DVDs,etc.

Desta forma foram elaborados vários relatórios personalizados, como recibo de empréstimo e devolução, carta cobrança, relatórios de débitos por turmas, estatísticas de empréstimos, etc. 


\section{Ações de Incentivo à Leitura}

Sabe-se que a leitura é um processo de contínuo aprendizado, ajuda a desenvolver a reflexão e o espírito crítico e é fonte inesgotável de informação para melhor compreender a si e ao mundo. Alguém acostumado a ler sabe onde buscar respostas para suas dúvidas e como se atualizar. $\mathrm{O}$ ato de decifrar ou interpretar bem o sentido das coisas ajuda a formar seres pensantes preparados para a vida.

Um projeto de Incentivo à Leitura é uma importante ferramenta de inclusão social. Ele possibilita a ampliação do acesso aos diferenciados portadores de texto. Através do incentivo a leitura e à cultura da leitura, que o programa desenvolve nas salas e comunidades atendidas, a possibilidade de ampliar a capacidade de representação e comunicação de histórias pessoais e coletivas.

Pensando nisto, procurou-se desenvolver alguns projetos que favorecem a todos os segmentos de aprendizagem.

\subsection{Principais Projetos de incentivo a Leitura executados}

\subsection{Hora do Conto}

A Hora do conto amplia os horizontes da leitura, tornando a criança consciente da infinidade de livros de diversos temas, gêneros e estilos, capazes de satisfazer suas necessidades individuais e seus gostos, além de permitir a seleção de obras que mais se ajustem ao seu grau de maturidade psíquica e intelectual.

Também é possível desenvolver nos alunos, competências como:

- Imaginação;

- Criatividade;

- Curiosidade;

- Emoções (tristeza, raiva, etc.);

- Atenção;

- Gosto pela leitura; 
- Vocabulário (linguagem);

- Noção de seqüência;

- Raciocínio;

- Descoberta de outros lugares, tempos, cultura, etc;

O objetivo da "Hora do Conto" é ler e contar histórias de forma alegre e agradável, buscando atrair as crianças para o universo da literatura e, dessa maneira, ajudar na formação de novos leitores.

As sessões da "Hora do Conto" são realizadas, para as turmas da Educação Infantil, em horários previamente marcados na Agenda on-line da escola. Nesta agenda, a professora sugere um tema de literatura, de acordo com o seu planejamento de aula. Esta atitude reforça e enriquece o conteúdo a ser trabalhado em sala.

Cada história é adaptada e apresentada de forma distinta, utilizando técnicas como:

- O próprio livro;

- Ilustrações;

- Avental e expressão corporal;

- Álbum seriado;

- Lousa da Biblioteca;

- Data show;

- Televisão de caixa ou cineminha;

- Caixa de histórias;

- Teatro ( fantoches de vara, dedo, mão, papel, sombras, etc.);

\subsection{Encontro com Autores Mineiros}

Para aproximar o aluno aos mundos dos livros, elaborou-se o projeto "Encontro com autores Mineiros". Nesse projeto, além da Hora do Conto realizada habitualmente com os alunos, foi feita a apresentação dos autores convidados e apresentado um relato da trajetória de cada um deles. 
Os encontros com os Autores ocorreram em diversas Feiras de Literatura da escola. Foi uma experiência muito gratificante, pois os alunos se prepararam para o encontro com o Autor, lendo antecipadamente as suas obras para a participação em um bate-papo na biblioteca, seguido de uma sessão de autógrafos e fotos com o autor.

Dentre os nossos principais convidados, contou-se com a presença de Therezinha Casasanta e Regina Rennó, ambas autoras de livros infantis.

\subsection{Li, gostei e recomendo a Leitura}

O segundo segmento, que tem como público alvo os adolescentes do $6^{\circ}$ ao $9^{\circ}$ ano do Ensino Fundamental. Observa-se que nesta faixa-etária, os adolescentes não gostam de ler por obrigatoriedade; eles se interessam por leituras de livros que estão na moda e ficam antenados com as novas tecnologias como a internet.

A falta de interesse dos jovens brasileiros pela leitura tem gerado grandes prejuízos para o seu próprio aprendizado, pois a leitura é fundamental para o desenvolvimento crítico da mente.

Aplicou-se para este público, o "Projeto Li, Gostei e Recomendo a Leitura" em parceria com os professores de Língua Portuguesa e Literatura e o DTI (Departamento de Tecnologia e Informação), pois, de acordo com as Diretrizes da IFLA/UNESCO para Bibliotecas Escolares, 2002, “A cooperação entre os professores e o bibliotecário escolar é essencial para maximizar o potencial dos serviços da biblioteca".

Neste projeto, a turma de alunos visita a biblioteca em horário previamente agendado, e sob a orientação do professor, escolhe o livro de seu interesse. $\mathrm{O}$ aluno leva o livro emprestado e tem sete dias para ler e fazer uma sinopse dele. A sinopse é apresentada em sala de aula e o professor elege as melhores produções.

Após esta seleção, o aluno é encaminhado ao DTI, para a publicação de sua sinopse no site da escola. Nesta etapa, o aluno é orientado a fazer um upload da imagem da capa do livro e transcrever o seu texto, tecendo um breve comentário sobre o livro e promovendo o mesmo a quem possa se interessar em lê-lo. 
Essas técnicas são utilizadas como caminho de incentivo à leitura de diferentes textos. São realizadas diversas ações e práticas que despertam a curiosidade e fornecem novas perspectivas de estudo, profissão e lazer.

Este projeto possui como objetivos principais: possibilitar a aproximação dos adolescentes com a Biblioteca; avaliar e destacar as competências do aluno selecionado, aguçar a curiosidade de seus colegas pela leitura do livro destacado no site da escola nos colegas e também favorecer as atividades de marketing da instituição, pois quem o visita estará de certa forma, avaliando a sua qualidade de ensino.

\subsection{Blog da Biblioteca}

Os blogs vêm se tornando a cada dia uma forma de comunicação das instituições com seus usuários. Vários profissionais utilizam-se dele como uma forma de divulgar seu conhecimento para a comunidade.

O blog da biblioteca (www.ient.com.br/andreia) tem sido utilizado para informar e divulgar aos usuários, atividades relativas ao seu funcionamento. Publica-se no blog assuntos relacionados à educação, comportamento, atualidades e informações como: novas aquisições e outras novidades da biblioteca.

Alunos, funcionários, professores e pais de alunos, acessam o blog da Biblioteca Novos Tempos e através dos comentários de seus leitores, recebe-se um feedback, muito importante para as tomadas de decisões.

\section{Considerações Finais}

Acredita-se que na Sociedade da Informação, a biblioteca escolar tem seu espaço garantido como sistema de informação.

A biblioteca deve neste sentido, incorporar o paradigma de mudança, próprio da atual sociedade e da cultura lúdica orientando os seus usuários e dando destaque, em especial, ao livro de literatura, no contexto das crianças e jovens. Desta forma, a biblioteca escolar cumprirá com o seu papel de favorecer o desenvolvimento educacional, cultural e social da comunidade. 
Com relação ao incentivo à leitura, acreditamos ter alcançado o objetivo proposto, pois se percebeu mudanças nos hábitos dos usuários e na freqüência à Biblioteca.

\section{ANEXOS}

Encontro com autores Therezinha Casasanta

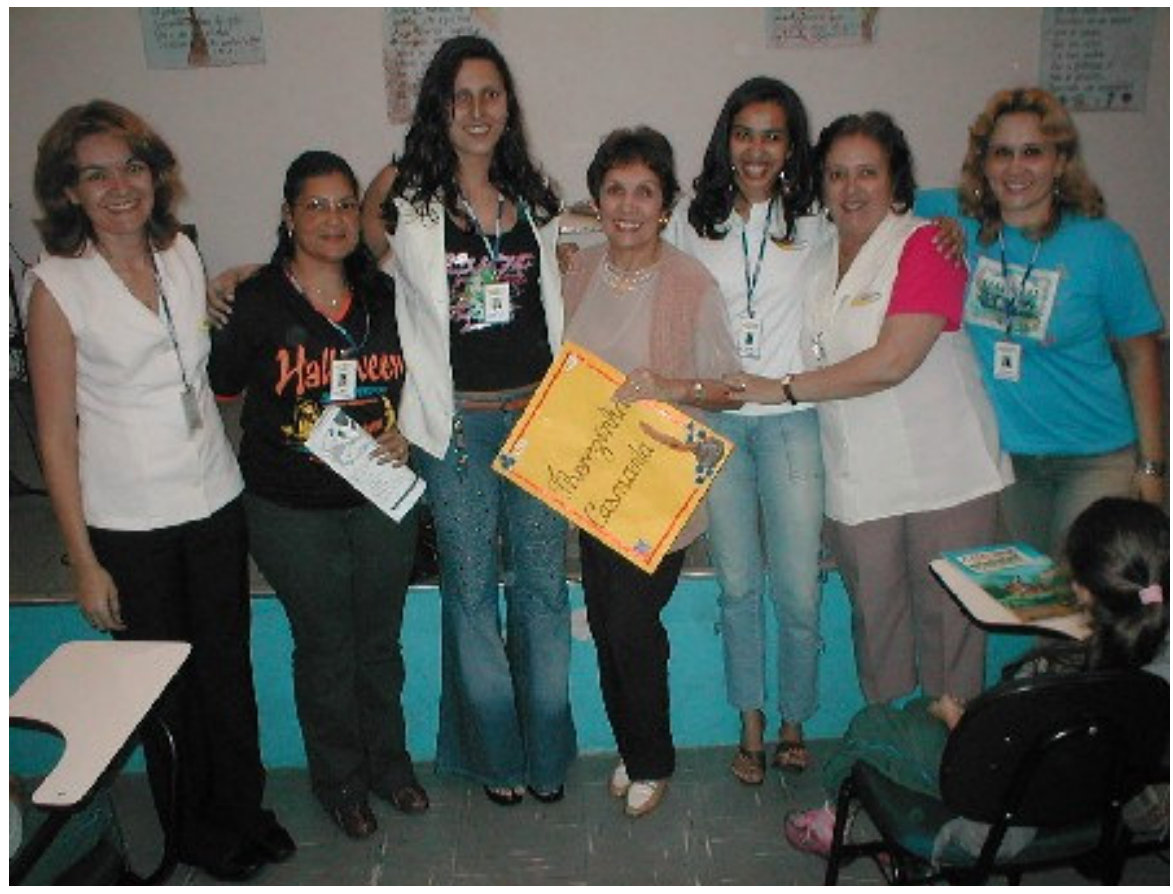

2004

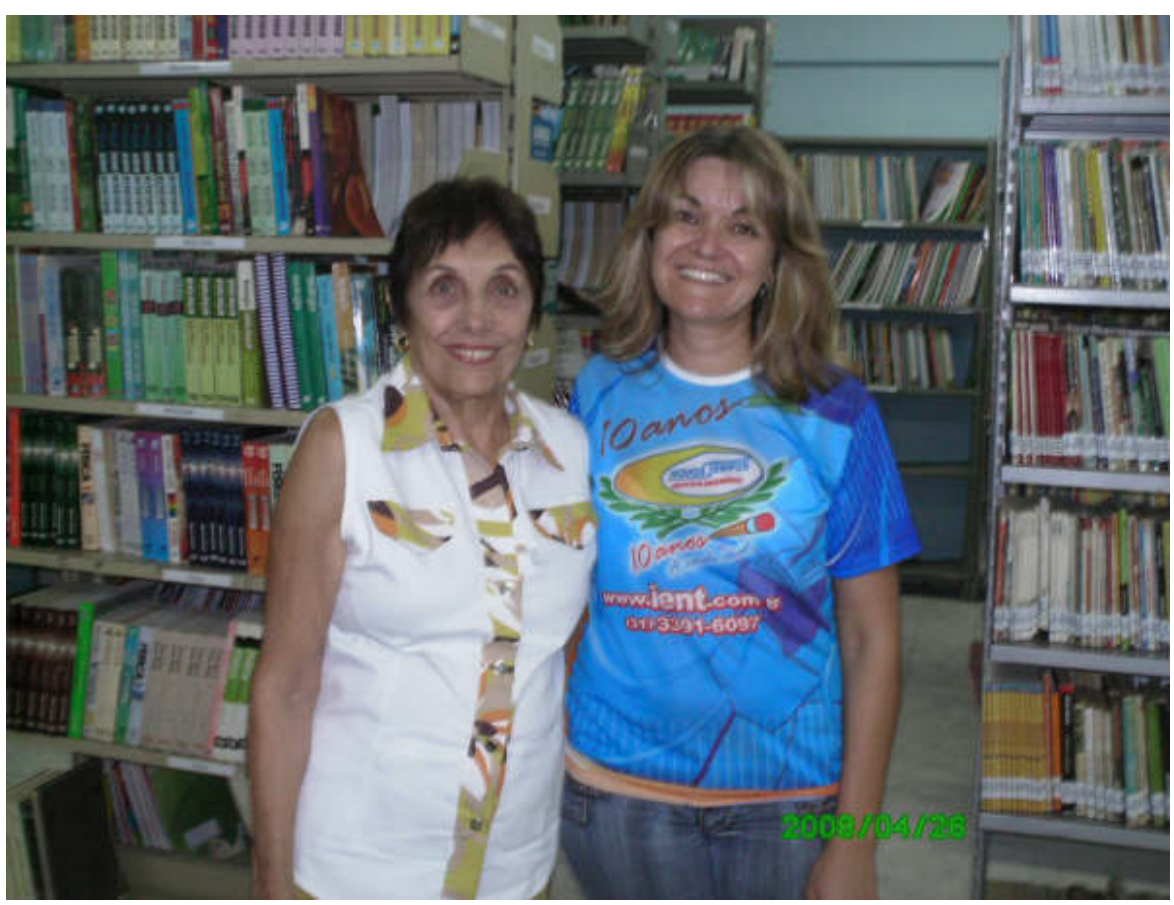

2008

Bibl. Esc. em Rev., Ribeirão Preto, v. 2, n. 1, p. 96-105, 2013. 


\section{Encontro com autores (Regina Rennó)}

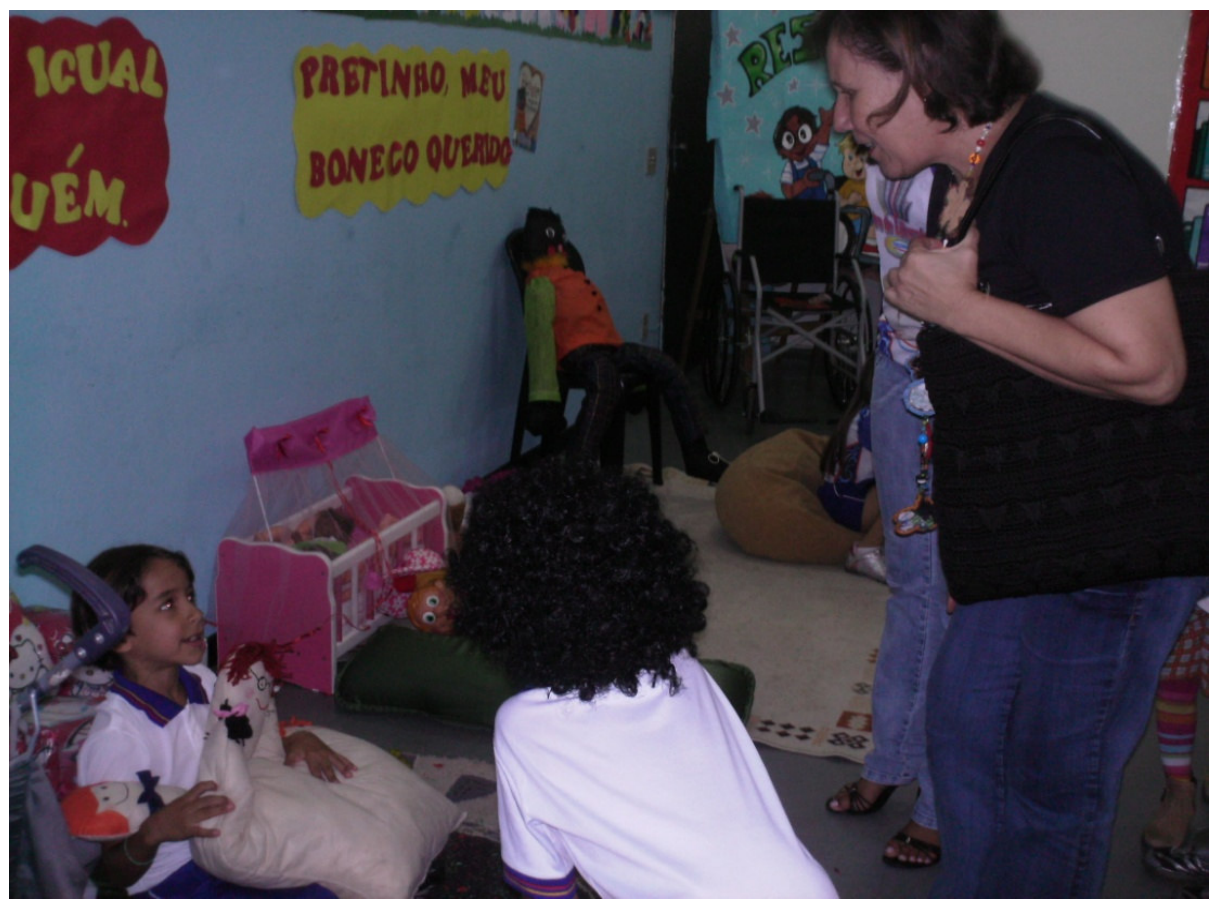

Tarde de autógrafos - 2009

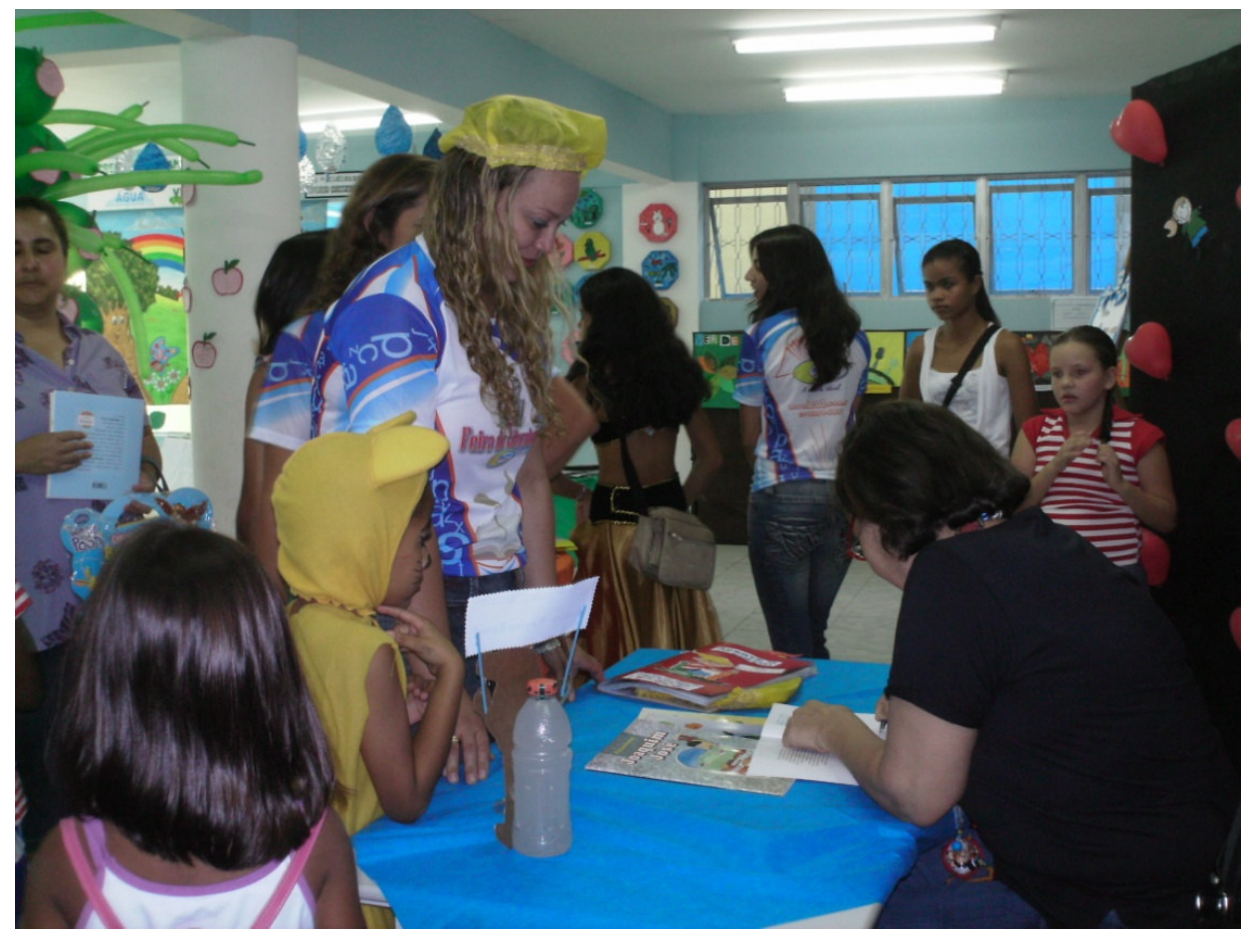


IV Prêmio Carol Kuhlthau

\section{Projeto Hora do Conto}

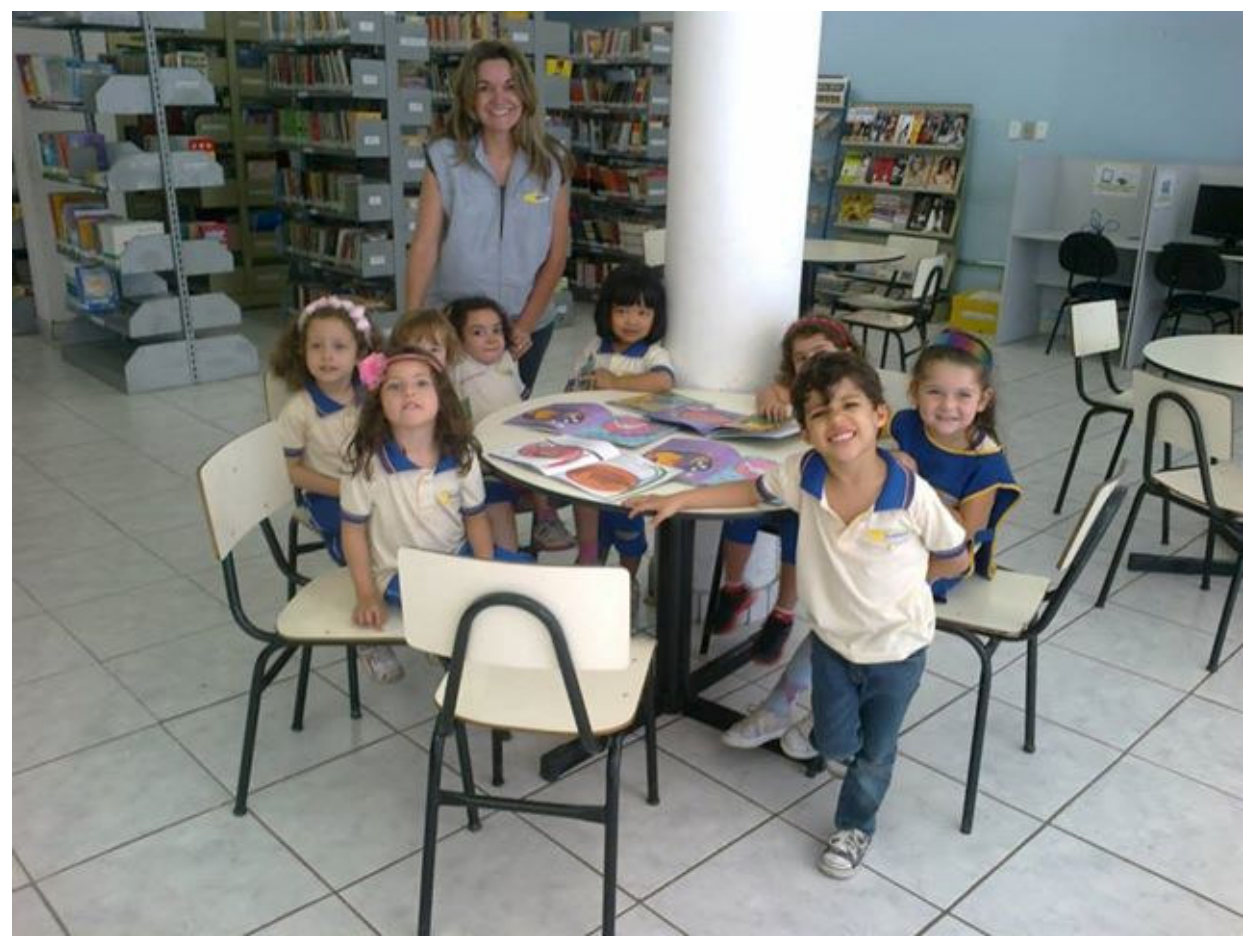

Projeto Li, gostei e recomendo

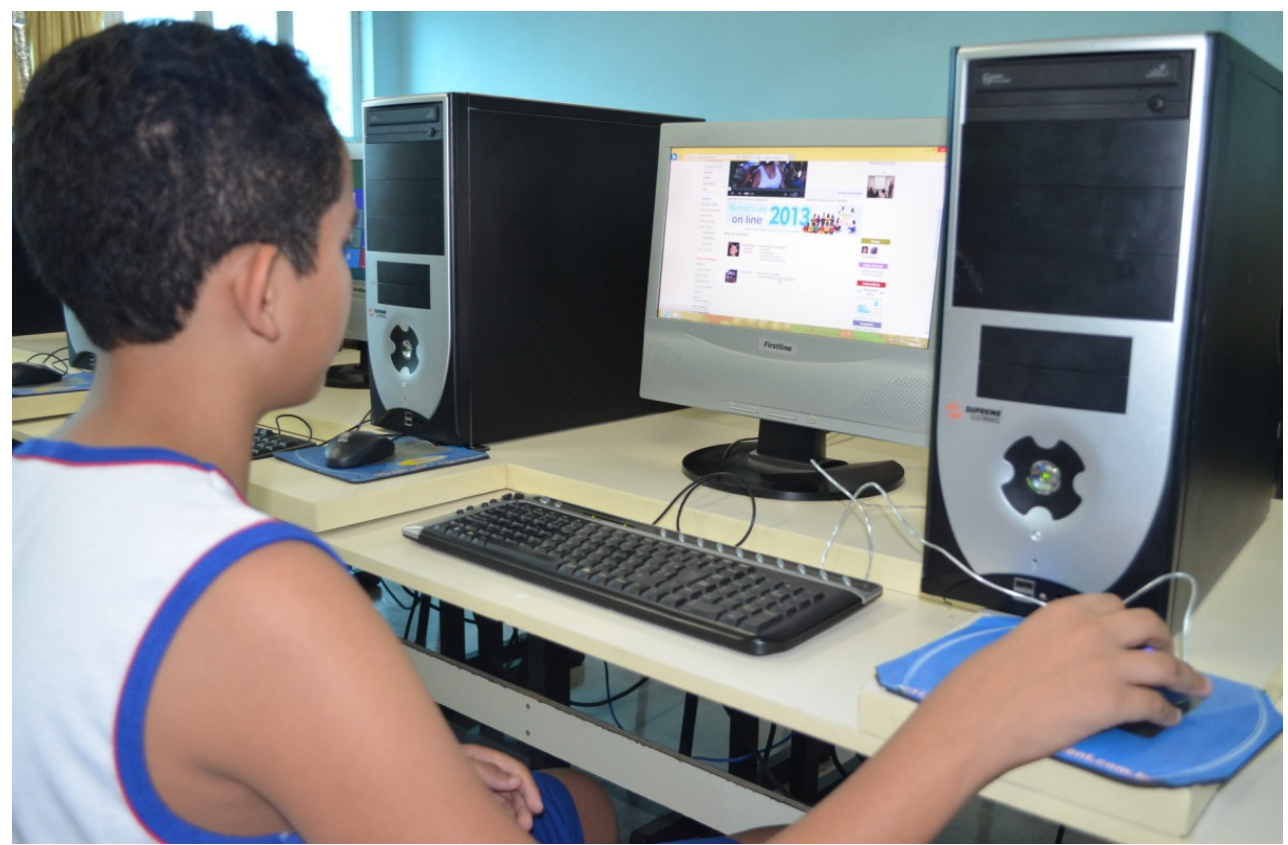

